\title{
Estudo da Execução de Serviços em Órbita de Satélites Usando um Braço Robótico Cooperativo com o Controle de Atitude
}

\author{
Anderson Brazil Nardin Evandro Marconi Rocco \\ Instituto Nacional de Pesquisas Espaciais - Divisão de Mecânica Espacial e Controle \\ 12227-010, São José dos Campos, SP \\ E-mails: anderson.nardin@inpe.br, evandro.rocco@inpe.br
}

\begin{abstract}
RESUMO
\end{abstract}
Neste estudo é analisada a aplicação de um sistema robótico em ambiente espacial, levando em consideração as perturbações causadas à atitude, em virtude do acionamento dos mecanismos robóticos durante a realização de serviços em órbita. O trabalho realizado sugere ganhos consideráveis ao empregar-se modelos que contemplem a correção dinâmica dos erros de posicionamento do referencial do braço robótico, que por sua vez, atua simultaneamente ao controle de atitude do satélite. Atividades robóticas de serviços em órbita têm se tornado comuns devido ao surgimento de novas tecnologias na área de rendezvous, docking $\mathrm{e}$ berthing. O braço robótico que serve de objeto de estudo neste trabalho consiste de um manipulador revoluto com três juntas rotativas e três graus de liberdade em configuração Torcional-Rotacional-Rotacional (TRR) movendo-se no espaço. Configuração tal que o confere aplicabilidade diversificada e notória utilidade em atividades de serviço em órbita. A análise dos erros de posicionamento ocasionados pelos movimentos de extensão e rotação do aparato nos possibilita uma visão mais clara sobre as estratégias necessárias para o uso futuro deste tipo de tecnologia.

Neste trabalho proponho o uso de um manipulador robótico servindo como ferramenta a contribuir com a efetivação de serviços em ambiente espacial e sanando problemas de controle encontrados quando do uso de outros atuadores para tal finalidade. É, portanto, fundamental que se tenha boa idéia das perturbações causadas à atitude do satélite em decorrência da atuação do braço robótico acoplado. Neste sentido nos concentraremos na análise dos torques perturbadores visto que a base do robô não pode ser considerada, para fins de posicionamento preciso, como sendo de um sistema inercial.

A perda da missão pode ser ocasionada por falha prematura de equipamentos do satélite, por isso as agências espaciais têm investido no desenvolvimento de serviços em órbita (OOS - On Orbit Service). OOS inclui diversas atividades de um veículo espacial [1] como montagem, reparo, resgate, aprimoramento, reabastecimento, recuperação e manutenção. Esses serviços podem estender a vida útil dos satélites, melhorar a capacidade dos sistemas espaciais, reduzir custos de operação, e até mesmo contribuir para a mitigação dos detritos espaciais. É imprescindível o domínio das técnicas de rendezvous e docking, bem como, do controle de atitude para executar serviços em órbita em missões do tipo montagem de grandes unidades, reabastecimento de estações, troca de tripulação entre veículos, reparo de satélites, entre outras.

Primeiramente, obtemos um modelo que represente, por meio de um algoritmo implementado, a forma como responde um manipulador robótico durante simulação com parâmetros controlados. A configuração de robô articulado (antropomórfico) ou revoluto assemelha-se a um braço humano.

Observa-se que é possível calcular a posição cartesiana no espaço, bem como a orientação do punho, com base no conhecimento dos ângulos das juntas. Este equacionamento é conhecido como cinemática direta. O cálculo das posições angulares das juntas a partir da posição no espaço do órgão terminal consiste, portanto, na cinemática inversa.

O cálculo da cinemática, tanto direta quanto inversa, requer o conhecimento do comprimento dos elos com precisão adequada, bem como os ângulos de torção entre juntas, ou seja, necessitamos definir tais constantes em nosso modelo computacional e para tanto a chamada notação de Denavit-Hartenberg permite obter o conjunto de equações que descreve a cinemática de uma junta com relação à junta seguinte vide [2]. Assim podemos ter uma visão matematizada da estrutura do robô para inserirmos no algoritmo.

A Fig. 1 e a Fig. 3 mostram o mecanismo do qual obtivemos as equações para solução da cinemática inversa, ou seja, dada a posição desejada para o órgão terminal encontram-se os ângulos das juntas capazes de levar a extremidade do robô a tal posição. A modelagem do comportamento do satélite é obtida por meio do Satellite Attitude Simulator (SAS) desenvolvido em [3] e [4], onde o movimento de atitude é calculado a cada passo da simulação. Na arquitetura do simulador Fig. 2, a atitude de referência é comparada continuamente com a posição angular atual do veículo espacial. Um sinal de erro é gerado por meio da 
diferença entre os estados atual e de referência. $O$ sinal de erro é então enviado a um controlador proporcional integral derivativo (PID) cuja lei de controle é definida pela Eq. (1), onde $K_{p}$ é o ganho proporcional, $K_{i}$ o ganho integral, $K_{d}$ o ganho derivativo e $\operatorname{er}(t)$ é o sinal de erro.

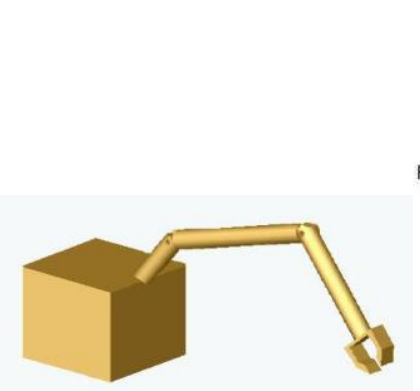

Fig. 1 Arranjo braço-satélite.

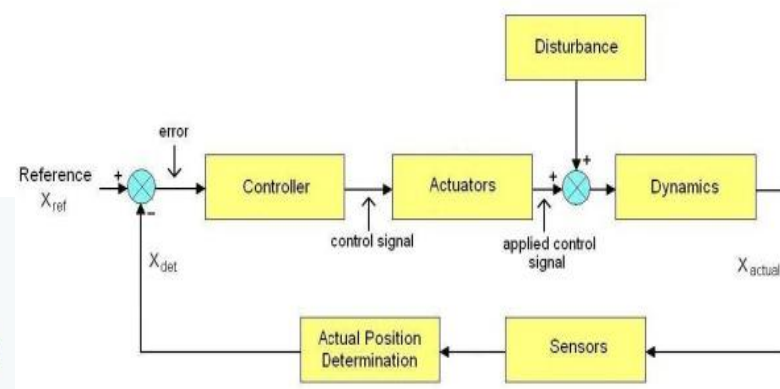

Fig. 2 Arquitetura de controle.

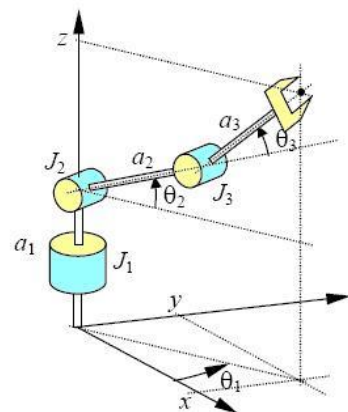

Fig. 3 Braço revoluto $T R R$.

$c(t)=K_{P} \operatorname{er}(t)+K_{I} \int \operatorname{er}(t) d t+K_{D} \frac{d}{d t} \operatorname{er}(t)$

Usando as técnicas da teoria de controle, o controlador gera um sinal visando reduzir o erro, no regime transitório e também o erro de estado estacionário, que é enviado para os atuadores, que representam um sistema de propulsão, por exemplo. Da simulação do algoritmo são obtidos os seguintes resultados apresentados sob forma de gráficos, caracterizando um determinado movimento do robô e compondo o que seria um possível serviço em órbita realizado pelo braço acoplado ao satélite livre no espaço.

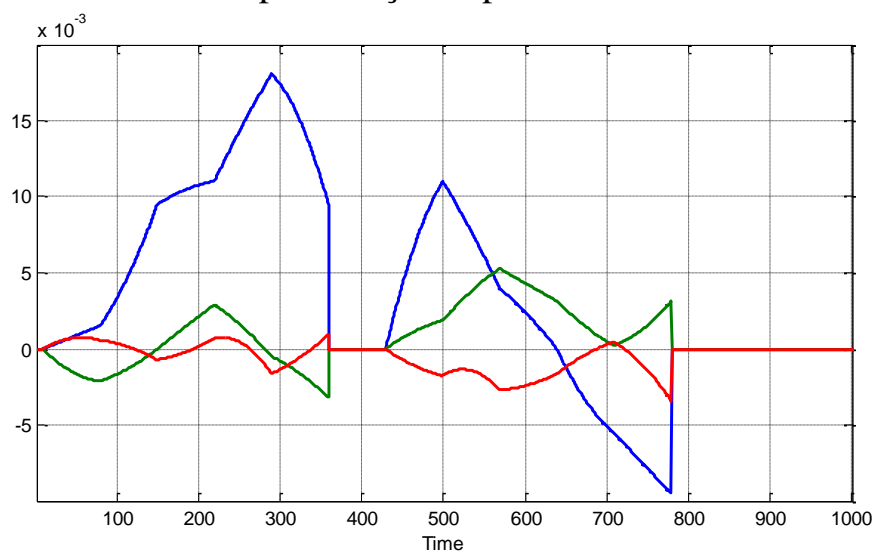

Fig. 4 Distúrbios em X (azul), Y (verde) e Z (vermelho) ( $\mathrm{rad} / \mathrm{s})$ x Tempo (s).

A Fig. 4 apresenta como se comportam os torques no satélite em cada direção ao longo do tempo por consequência do movimento do braço robótico. Estes torques são decorrentes do movimento escolhido e deverão ser tratados como perturbações pelo sistema de controle do satélite a fim de atuar em sua correção de posicionamento. A atuação conjunta e cooperativa dos sistemas de controle do braço robótico e do satélite mostra-se, portanto, uma abordagem promissora na mitigação dos erros de posicionamento.

Palavras-chave: Robótica, Satélites Artificiais, Manobras Espaciais

\section{Referências}

[1] Arantes JR., G.; Rocco, E. M.; Komanduri, A. S., Far and close approaching strategies for rendezvous and docking operations applied to on-orbit servicing. In: SIVASUNDARAM, S. (Ed.). Mathematical analysis and applications in engineering aerospace and sciences. Embry Riddle Aeronautical University, Cambridge, USA, 2010.

[2] Craig, J.J., Introduction to Robotics: Mechanics and Control, 3rd edition, Pearson Education Inc., 2005.

[3] Rocco, E. M., Perturbed orbital motion with a PID control system for the trajectory. In: $14^{\circ}$ Colóquio Brasileiro de Dinâmica Orbital, Águas de Lindóia, 2008.

[4] Rocco, E. M.; Costa Filho, A.C; Carrara, V., Effect the coupling between attitude and orbital control in maneuvers using continuous thrust. Minissimpósio: Aerospace Engineering. In: 10 a Conferência Brasileira de Dinâmica, Controle e Aplicações, 2011. 